\title{
Clinical Management of Asthma by Respira
Specialists versus General Practitioners: Questionnaire Survey Results Over 6 Years
}

This article was published in the following Dove Press journal: International Journal of General Medicine

\author{
Megumi Hamaguchi ${ }^{1}$ \\ Yasuyuki Taooka (D) $^{2}$ \\ Mika Nakao' \\ Kazuhisa Nakashima' \\ Takamasa Hotta (D) \\ Yukari Tsubata (D) \\ Shunichi Hamaguchi ${ }^{1}$ \\ Akihisa Sutani ${ }^{3}$ \\ Takeshi Isobe' \\ 'Department of Internal Medicine, \\ Division of Medical Oncology and \\ Respiratory Medicine, Shimane University \\ Faculty of Medicine, Izumo, Shimane, \\ Japan; ${ }^{2}$ Respiratory Medicine, Medical \\ Corporation JR Hiroshima Hospital, \\ Hiroshima, Hiroshima, Japan; \\ ${ }^{3}$ Respiratory Medicine, Sutani Clinic, \\ Izumo, Shimane, Japan
}

Correspondence: Yukari Tsubata Department of Internal Medicine, Division of Medical Oncology and Respiratory Medicine, Shimane University Faculty of Medicine, 89-I Enya-Cho, Izumo, Shimane, 693-850I, Japan

Tel $+8|-853-23-258|$

Fax +8I-853-20-258I

Email ytsubata@med.shimane-u.ac.jp
Background: In Japan, the Ministry of Health, Labour and Welfare population dynamics investigation showed a decrease in the number of deaths related to asthma in recent years. In 2016, the mortality rate was 1.2 deaths per 100,000 population. There were regional differences; Shimane Prefecture had a higher mortality rate (1.6 deaths per 100,000 population in 2016) than other prefectures. In this study, to clarify problems in asthma treatment, we evaluated the status of asthma treatment in Shimane Prefecture.

Methods: We performed three cross-sectional questionnaire surveys, in October 2006, February 2009, and February 2012. We received responses from 78 clinics and hospitals. Subjects were patients with bronchial asthma over 14 years of age who regularly visited an outpatient clinic. Survey items included smoking status, control status assessed using the Asthma Control Test (ACT), treatment, and medication adherence. Doctors board-certified by the Japanese Respiratory Society were defined as respiratory specialists (RSs) and other doctors were defined as general practitioners (GPs). We compared various factors between the RS and GP groups.

Results: Clinical data of 2159 patients were available for analysis. The proportion of patients with ACT score $\geq 20$ points increased significantly between 2006 and 2012 in the GP group. The rate of inhaled corticosteroid use increased in the GP group from $63.6 \%$ to $76.4 \%$.

Conclusion: It was suggested that asthma control and the rate of inhaled corticosteroid use were related. We should continue educating GPs about asthma treatment.

Keywords: questionnaire, bronchial asthma, asthma control test, adherence, general practitioners

\section{Introduction}

The increase in the number of bronchial asthma cases and asthma-related deaths is a serious public health problem in Japan and other countries. In Japan, the Ministry of Health, Labour and Welfare population dynamics investigation showed that asthmarelated deaths have decreased from 6370 in 1980 to 1728 in 2013. The most important factor related to this decrease was the widespread use of inhaled corticosteroids (ICSs). ${ }^{1}$ However, the prevalence of asthma-related deaths in Shimane Prefecture remained higher than in other prefectures of Japan. Shimane Prefecture is located in the western part of Japan. It is mostly rural, and in 2009 more than $29.0 \%$ of the population was elderly. This is higher than that of Japan as a whole (22.7\%). Most asthma-related deaths involve elderly patients ( $\geq 65$ years). The large population of elderly people in Shimane Prefecture is one of the reasons for the large number of asthma deaths in this region. Since bronchial asthma is a common disease, both 
respiratory specialists (RSs) and general practitioners (GPs) should be involved in the treatment of asthma. In Japanese medical insurance systems, patients can choose their own physician, either a RS or GP. We previously reported that elderly patients with asthma treated by GPs underestimated by GPs the severity of their asthma and such patients were undertreated. $^{2}$ Those results stress the need to engage patients in educational activities.

We have been worked on educating patients and GPs about asthma treatment since 2005. For patients, we have been conducting educational activities on pathophysiology of asthma and treatment methods through public lectures. Public lectures were held once or twice a year, and repeated guidance was given on asthma and allergies, smoking cessation, and pneumonia prevention. For GPs, we have conducted training about the proper use of asthma medications according to guidelines and the importance of inhalation guidance. Once a month, we gave a lecture on bronchial asthma and respiratory diseases for GP and held a briefing session on new asthma treatment drugs. Education about controlling bronchial asthma was conducted in accordance with Japanese asthma prevention and management guidelines. We have conducted a questionnaire survey at three time points to investigate how asthma treatment in Shimane Prefecture has changed as a result of those educational activities. The purpose of this study was to evaluate the actual conditions of patients with asthma in Shimane Prefecture and compare RS versus GP management. Only a few studies have investigated differences in longitudinal management of patients with asthma by RSs and GPs.

\section{Methods}

\section{Study Design and Study Subjects}

This is a longitudinal follow-up questionnaire survey. We conducted surveys in October 2006, February 2009, and February 2012. Figure 1 shows the content of the questionnaire that we used, translated from Japanese. We asked for the participation of clinics and hospitals that advocate internal medicine. We sent the questionnaire to the clinics and

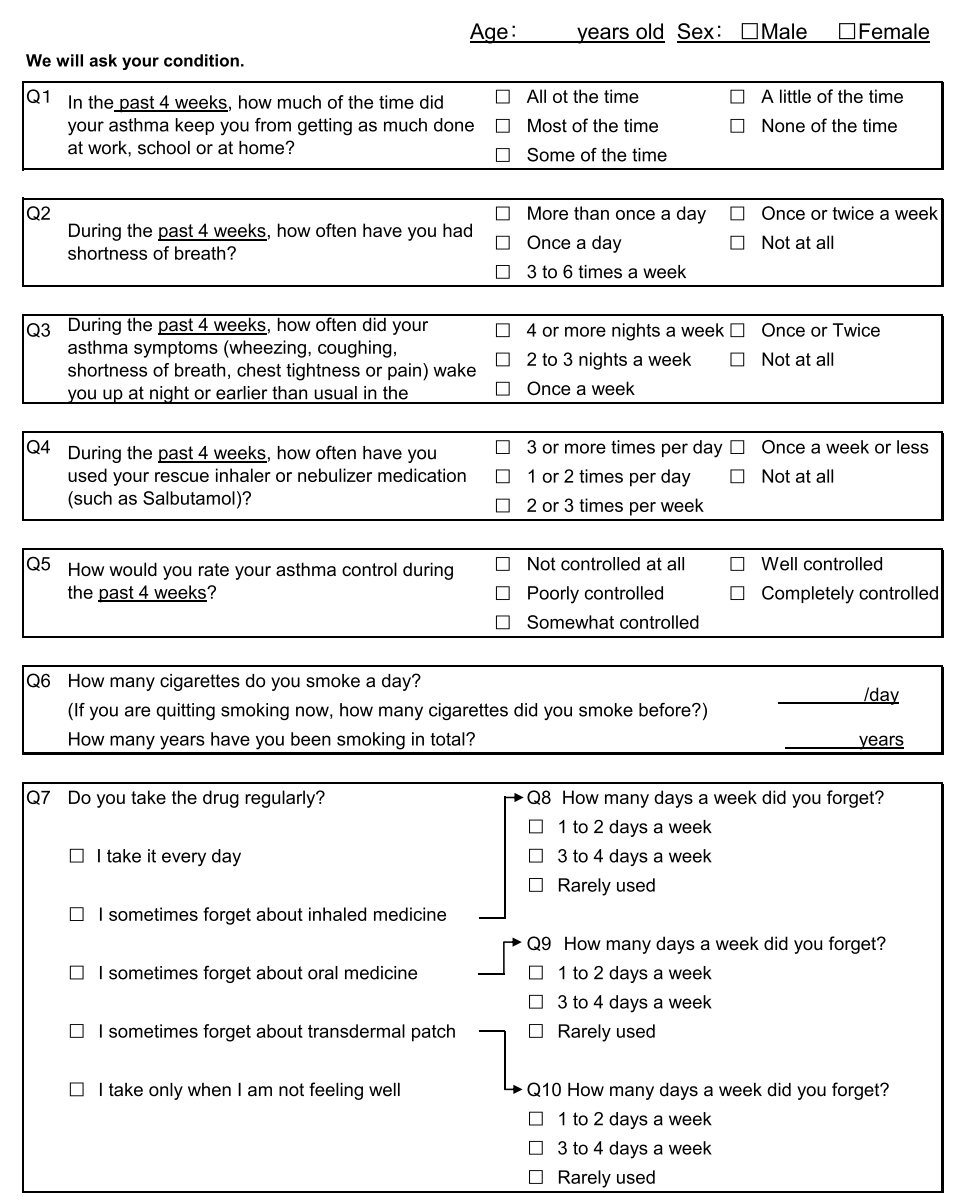

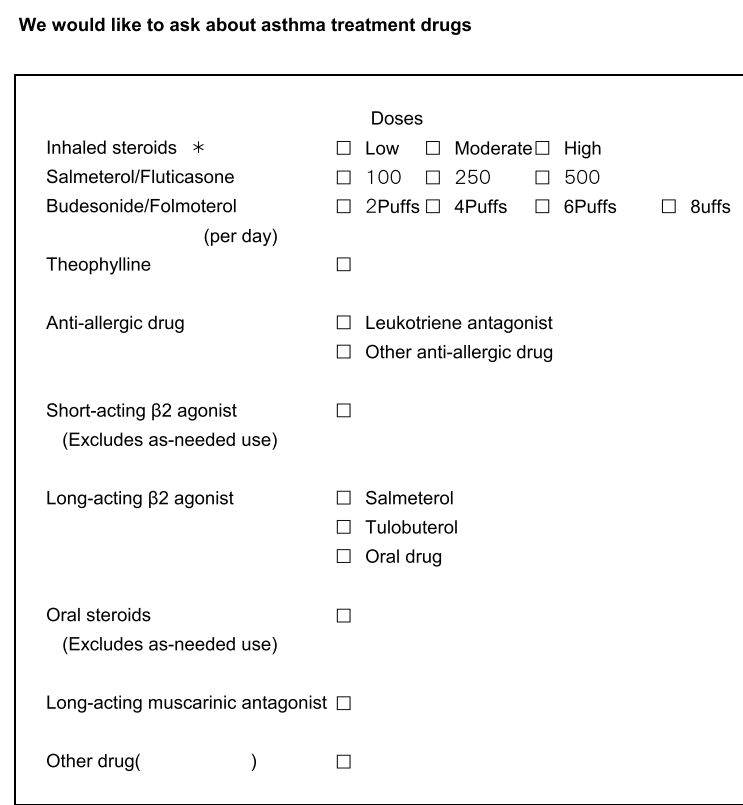

$*$ Inhaled steroid dose $(\mu \mathrm{g})$

\begin{tabular}{|l|c|c|c|}
\hline \multicolumn{1}{|c|}{ Inhaled steroid } & Low dose & Moderate dose & High dose \\
\hline Fluticasone & $100 \sim 200$ & $250 \sim 400$ & $450 \sim 800$ \\
\hline Beclomethasone & $100 \sim 200$ & $250 \sim 400$ & $450 \sim 800$ \\
\hline Ciclesonide & $100 \sim 200$ & $300 \sim 400$ & $500 \sim 800$ \\
\hline Mometasone & $100 \sim 200$ & $300 \sim 400$ & $500 \sim 800$ \\
\hline Budesonide & $200 \sim 400$ & $500 \sim 800$ & $900 \sim 1600$ \\
\hline
\end{tabular}

Figure I Questionnaire content: the questionnaire was originally written in Japanese. Copyright 2002 by QualityMetric Incorporated. Asthma Control Test is a trademark of QualityMetric Incorporated. GSK. Asthma Control Test. Available from: https://www.asthmacontroltest.com/en-au/welcome/. ${ }^{18}$ 
hospitals that offered to participate. We secured the participation of 78 clinics and hospitals (Supplementary). Questions on the left side were answered by the patient. Questions on the right side were answered by the attending physician. Doctors at each facility conducted a questionnaire survey on the status of asthma control as assessed by the Asthma Control Test (ACT), treatment status, and medication adherence for their patients with bronchial asthma. Patient background data including age, sex, and smoking status were also collected. The anonymous questionnaire was collected one month after it was distributed. All patients met the following inclusion criteria: (1) age $\geq 14$ years and (2) under treatment for bronchial asthma. This questionnairebased study had an opt-out observational design. Doctors at medical institutions verbally agreed to participate in the study and conducted the questionnaire survey. For minors, the research content was explained verbally using plain language, and consent was obtained verbally from the person and parent or guardian. All participants provided informed consent to take part in this study. Doctors who were boardcertified members of the Japanese Respiratory Society were defined as RSs. Other doctors were defined as GPs. We compared the RS and GP patient groups in terms of various factors. This study was performed with the approval of the Ethics Committee at the Shimane University Faculty of Medicine in Shimane Prefecture, Japan in accordance with the Declaration of Helsinki (Notification number 400; 2008-09-16).

\section{Questionnaire Content}

\section{Asthma Treatment}

We examined whether patients were using an ICS, longacting $\beta_{2}$ agonist (LABA), theophylline, leukotriene receptor antagonist (LTRA), long-acting antimuscarinic agent (LAMA), or anti-allergic. LABAs were included in ICS combinations. ICS dose was also examined.

\section{Evaluation of Asthma Control Using the ACT}

We used the ACT to evaluate asthma control. ${ }^{3}$ GlaxoSmithKline granted permission for the use of the Japanese version of the ACT, a trademark of QualityMetric. ACT included five questions that assess activity limitation, shortness of breath, night-time symptom and awakenings, use of rescue medications, and patient overall rating of asthma control over the previous 4 weeks. The questions are scored from 1 (worst) to 5 (best), and the score is the sum of the scores for the five questions. The sum of the scores of the five questions yields the total ACT score (range, 5-25). A total ACT score of 25 represents complete control of asthma, 20-24 good control, and $<20$ poor control. A high ACT score was defined as $\geq 20$ points.

\section{Adherence for Asthma Medication}

Status of medication adherence was examined starting with the 2009 questionnaire. The relationship between adherence and route of administration was also examined.

\section{Statistical Analysis}

Statistical analysis was performed using the Statistical Package for the Social Sciences software program, version 20.0 (IBM Corp., Armonk, NY, USA). Differences in asthma control rates and rates of ICS use by survey year were assessed using the chi-square test with BenjaminiHochberg false discovery rate procedure for multiple comparisons. Differences were considered statistically significant when $P<0.05$.

\section{Results}

\section{Outline of the Questionnaire and Patient Demographics}

With the participation of 78 clinics and hospitals, there were 2159 respondents with valid results (Table 1). The

Table I Outline of Questionnaire

\begin{tabular}{|l|c|c|c|}
\hline Survey Year & $\mathbf{2 0 0 6}$ & $\mathbf{2 0 0 9}$ & $\mathbf{2 0 1 2}$ \\
\hline Number of participating facilities & 51 & 50 & 56 \\
\hline Number of patient questionnaires & 664 & 813 & 682 \\
\hline Sex, male/female & $312 / 352$ & $380 / 433$ & $321 / 361$ \\
\hline Median age (range), years & $68(15-100)$ & $69(15-94)$ & $70(15-97)$ \\
\hline Number of RSs/GPs & $268 / 396$ & $411 / 402$ & $280 / 402$ \\
\hline
\end{tabular}

Abbreviations: RS, respiratory specialist; GP, general practitioner. 


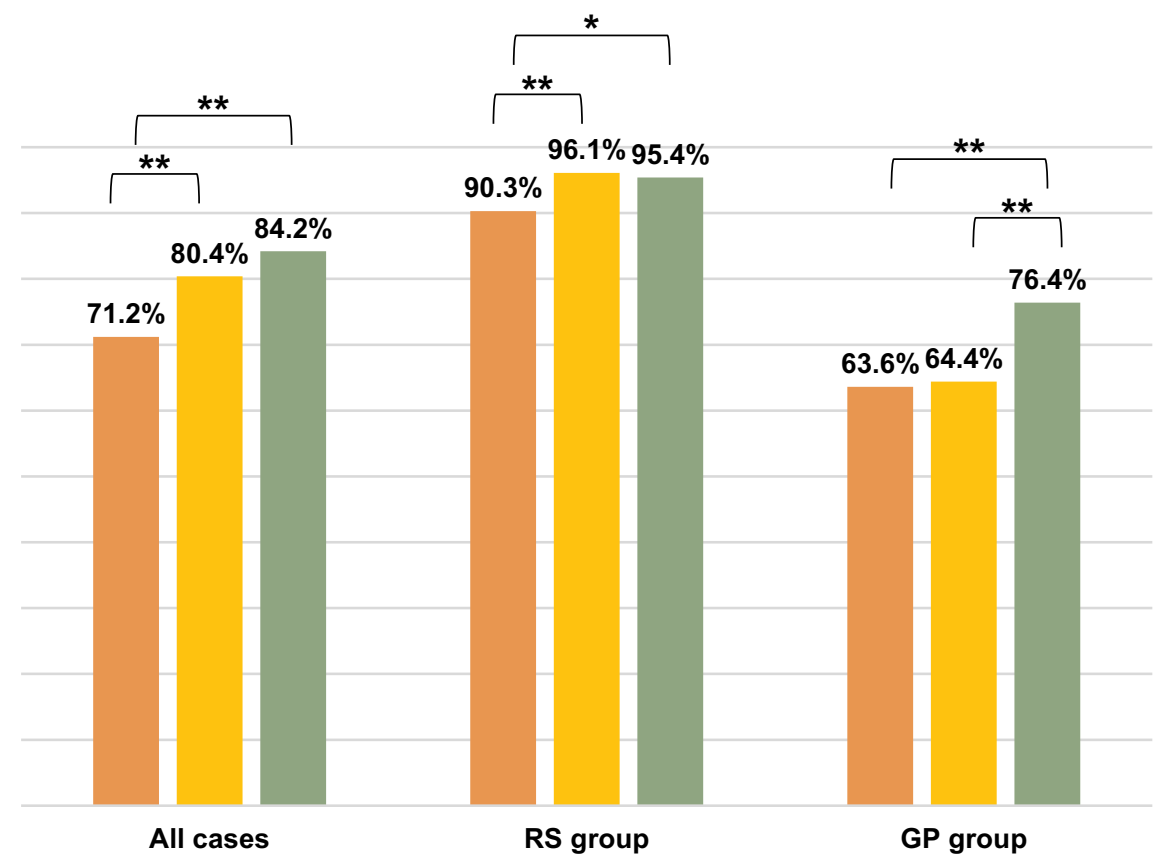

Figure 2 Inhaled corticosteroid use. Notes: $* P<0.05, * * P<0.01$. $2006 \quad 2009 \quad 2012$.

median age of patients was 68 years in 2006, 69 years in 2009 , and 70 years in 2012. The age range was 15 to 100 years. The number of patients under 65 years of age was 890 , and the number of patients over 65 years of age was 1269. The number of males and females was about the same. Most patients (55.6\%) were being treated by GPs.

\section{Asthma Treatment}

Figure 2 shows the rate of ICS use. The rate of ICS use was significantly higher in 2012 compared to 2006. Of note, there was a significant increase in the GP group $(P<0.001)$. All of the medications used to treat asthma are shown in Table 2. The rate of LABA use increased in both the RS and GP groups. Among patients who used LABAs, 56\% in 2009 and $84 \%$ in 2012 were using an ICS-LABA combination (formoterol/budesonide or salmeterol/fluticasone) (Figure 3).

The rate of theophylline and oral corticosteroid use decreased in each group. The rates of LTRA and LAMA use were higher in the RS group than in the GP group, respectively.

\section{Asthma Control}

Figure 4 shows the proportion of patients in the RS and GP groups with high total ACT scores. In the RS group, there were no differences by survey year. However, in the
GP group, the proportion of patients with high ACT scores in 2012 was significantly higher than the proportion in $2006(P<0.05)$.

\section{Medication Adherence}

The status of medication adherence was similar between the RS and GP groups. The overall rate of medication adherence was $65-69 \%$. Figure 5 shows the rate of medication adherence for inhaled agents, oral agents, and transdermal patches. Adherence for inhaled agents was poorer than adherence for oral agents and transdermal patches, respectively.

\section{Discussion}

In this longitudinal study, we found that the rate of ICS use in the GP group was significantly higher in the third survey compared to the rate in the first survey. This is the first analysis of ICS utilization in the GP group.

Risk factors for asthma exacerbation include inappropriate use of therapeutic agents and lack of adherence. ${ }^{4}$ It is necessary for physicians who treat asthma to appropriately assess asthma severity and prevent exacerbations according to guidelines. Unfortunately, not all GPs adhere to guidelines. ${ }^{5}$ Since respiratory medicine was established at Shimane University in 2004, we have continued to provide educational activities to spread standardized 
Table 2 Non-ICS Asthma Medications

\begin{tabular}{|c|c|c|c|}
\hline \multicolumn{4}{|l|}{ (A) RS Group } \\
\hline Survey Year (Total Number of Patients) & $2006(n=268)$ & $2009(n=4 I I)$ & $2012(n=280)$ \\
\hline Median age (range), years & $63(15-100)$ & $63(15-89)$ & $64(15-97)$ \\
\hline Sex, male/female & $126 / 142$ & $187 / 224$ & $127 / 153$ \\
\hline Theophylline (\%) & 40.3 & 29.0 & 21.8 \\
\hline LABA, including combinations with ICS, (\%) & 42.5 & 59.9 & 73.2 \\
\hline LTRA (\%) & 45.1 & 38.0 & 32.5 \\
\hline Anti-allergic agents (\%) & 9.1 & 3.2 & 11.8 \\
\hline LAMA (\%) & 4.5 & 12.2 & 13.2 \\
\hline \multicolumn{4}{|l|}{ (B) GP Group } \\
\hline Survey Year (Total Number of Patients) & $2006(n=396)$ & $2009(n=402)$ & $2012(n=402)$ \\
\hline Median age (range), years & $72(16-99)$ & $74(16-94)$ & $73(20-96)$ \\
\hline Sex, male/female & $186 / 210$ & $193 / 209$ & $194 / 208$ \\
\hline Theophylline (\%) & 54.3 & 46.0 & 32.1 \\
\hline LABA, including combinations with ICS, (\%) & 21.5 & 47.3 & 62.7 \\
\hline LTRA (\%) & 26.0 & 37.3 & 25.9 \\
\hline Anti-allergic agents (\%) & 10.9 & 9.2 & 4.0 \\
\hline LAMA (\%) & 4.0 & 2.7 & 9.2 \\
\hline
\end{tabular}

Abbreviations: RS, respiratory specialist; GP, general practitioner; ICS, inhaled corticosteroid; LABA, long-acting $\beta_{2}$ agonist; LTRA, leukotriene receptor antagonist; LAMA, long-acting antimuscarinic agent.

asthma treatment consistent with guidelines to non-specialists. Lectures about asthma treatment or inhalation methods by specialists have been held every year. We have conducted a questionnaire survey every three years since 2006 to investigate changes in asthma control and management in Shimane Prefecture. We investigated how the situation related to asthma education changed with our educational activities using the questionnaire survey. It is rare for serial questionnaire survey results about bronchial asthma control and treatment to be reported.

These surveys over 6 years revealed that the rate of ICS use increased. In a Japanese survey with 30,000 asthma patients in 2013, the ICS prescription rate was $46.0 \%{ }^{6}$ Compared to this report, ICS use in our survey is higher. In particular, the rate of ICS use in the GP group had increased significantly. Asthma control was significantly improved only in the GP group. It was suggested that this is partly due to the significant increase in ICS usage in the GP group. In addition, the rate of LABA use in the GP group also increased. The rate of LABA use included patients who used ICS/LABA combinations. ICS/ LABA combinations have been shown to be more effective than ICS and LABA individually. ${ }^{7}$ The usefulness of ICS/LABA combination drug therapy being known to GPs probably led to a high rate of LABA use.

Conversely, the rate of theophylline use decreased in both the RS and GP groups. Similar results were seen in the past. Seki et al reported that the rate of theophylline use decreased significantly over 10 years in Miyazaki Prefecture. ${ }^{8}$ Theophylline preparations have more of a bronchodilating effect than an anti-inflammatory effect, but their bronchodilating action is weaker than that of LABAs. $^{8}$ Therefore, theophylline became a drug that should be considered for discontinuation before ICS and LABA for asthma control. Theophylline use seems to have decreased.

The rates of LTRA and LAMA use were higher in the RS group than in the GP group. LTRAs have a bronchodilator effect and an airway inflammation suppressive effect; they reduce asthma exacerbations and asthma 


\section{B}

A
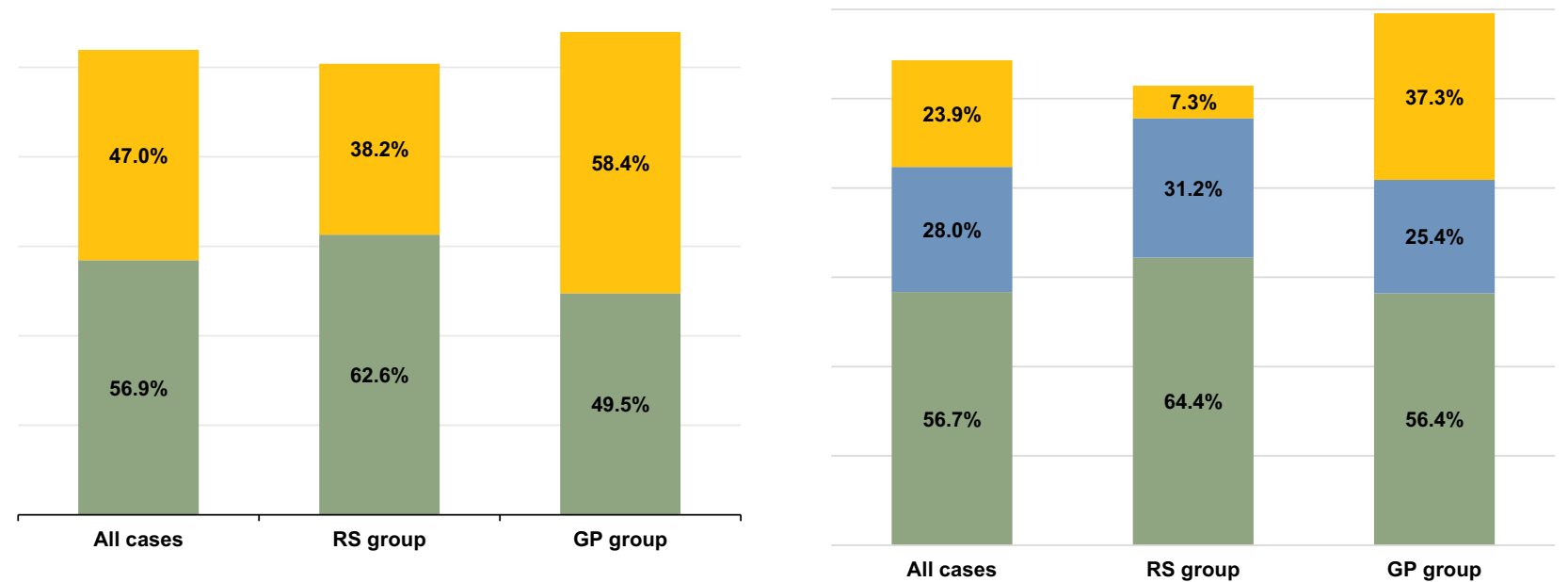

Figure 3 Use of ICS/LABA combination agents.

Notes: (A) 2009, (B) 2012. Another LABA. Formoterol/budesonide (released in 2010). Salmeterol/fluticasone (released in 2007)

Abbreviations: ICS, inhaled corticosteroid; LABA, long-acting $\beta_{2}$ agonist.

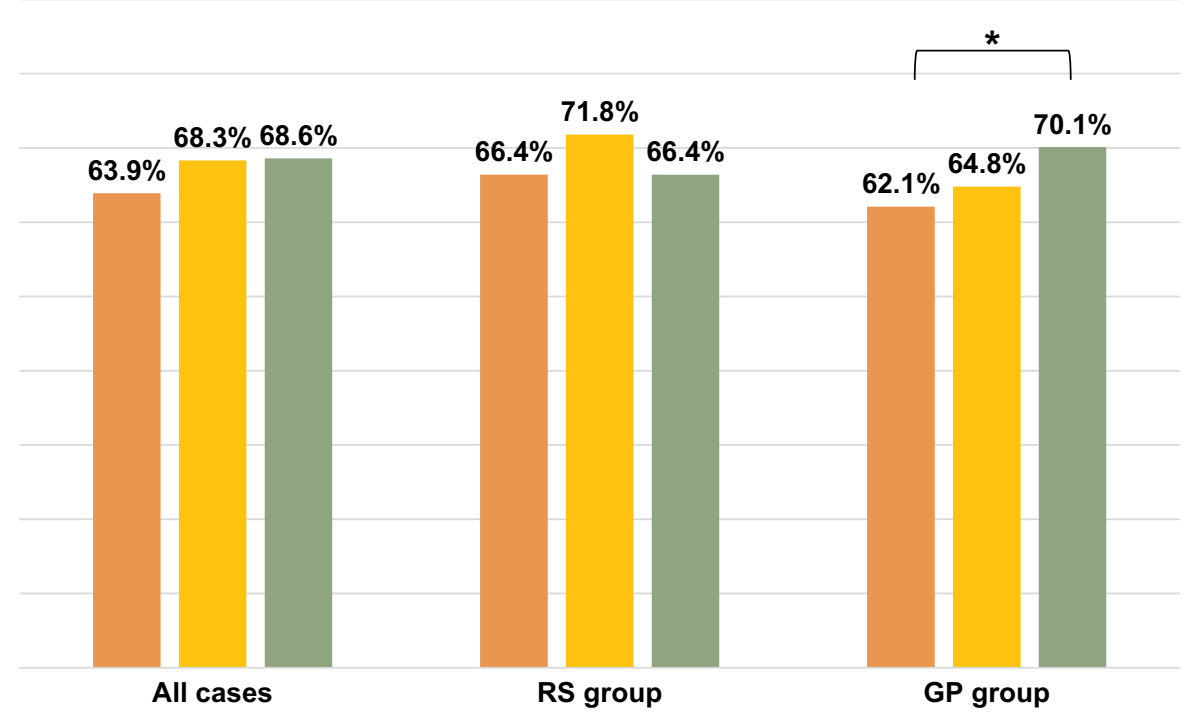

Figure 4 The rate of the patients with total ACT scores $\geqq 20$.

Notes: $* P<0.05$. $2006 \quad 2009 \quad 2012$

Abbreviation: ACT, asthma control test.

symptoms and significantly improve respiratory function and patient quality of life. ${ }^{9,10}$ They are also useful for long-term therapy in patients with asthma and allergic rhinitis and in patients with aspirin-induced asthma. ${ }^{11}$ It has been reported that LAMAs have the same effect as LABAs on asthma symptoms when used in patients using an ICS. ${ }^{12}$ LAMAs are effective in improving respiratory function and preventing exacerbations in patients with severe asthma. ${ }^{13}$ One reason that rates of LTRA and LAMA use were high might be because the RS group was familiar with these findings and used different drugs in individual patients.

The basis of asthma treatment is an inhaled medicine. Poor inhalation procedures lead to poor asthma control, increased risk of exacerbations, and more side effects. ${ }^{14}$ Adherence to inhaled medicines tends to be 


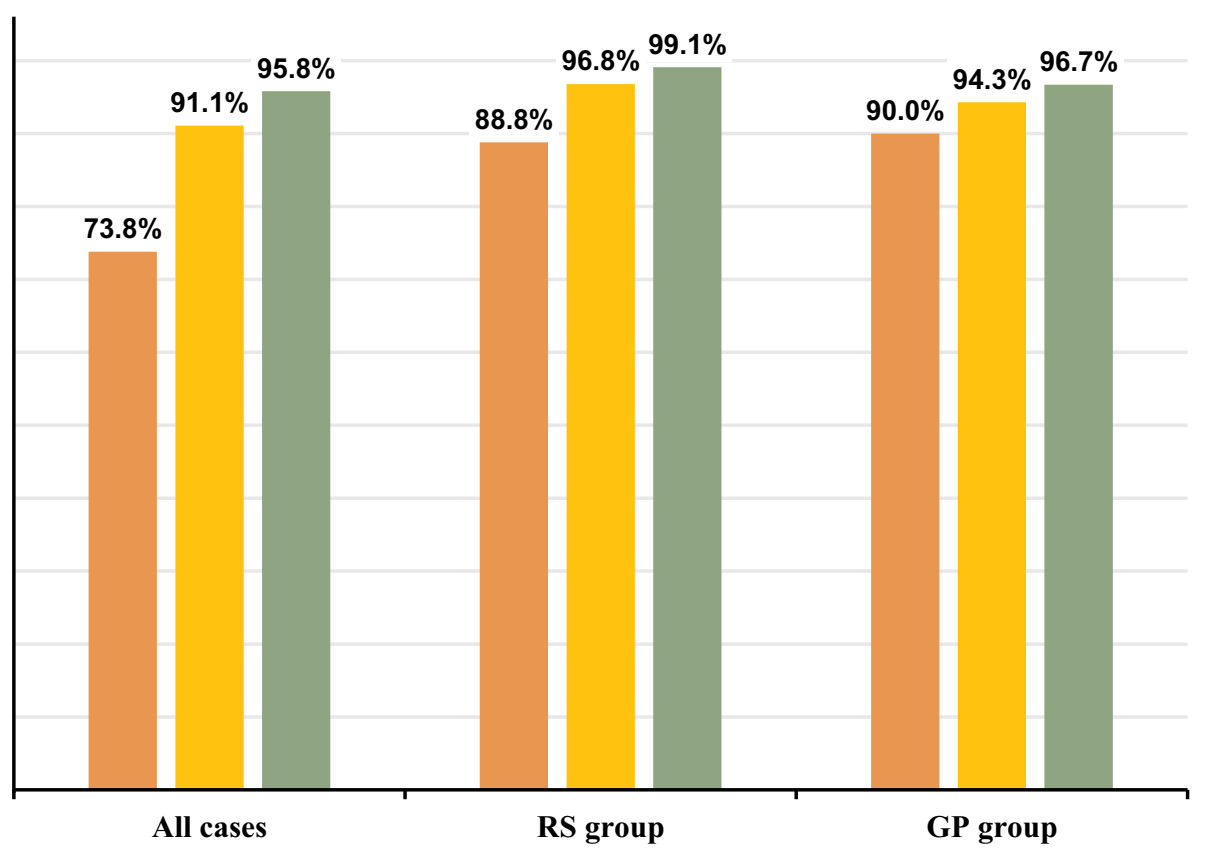

Figure 5 Adherence by route of administration.

Notes: Inhaled agents. Oral agents. Transdermal patches.

lower than adherence for oral medicines. It has been reported that medication adherence is lower in asthma and chronic obstructive pulmonary disease, conditions in which an inhaled medicine is the mainstay of treatment, than in other chronic diseases. ${ }^{15}$ It has been reported that an inhaled medicine has significantly lower adherence than a transdermal patch. ${ }^{16}$ Similarly, this study showed that adherence was lower for inhaled agents than for oral agents or transdermal patches. In addition, erroneous operation is often a problem with inhaled medicines. One study showed that erroneous operation occurred at a high rate (approximately 15\%) among patients aged 75 years or over, ${ }^{17}$ suggesting that it might be necessary to repeatedly teach inhalation techniques to elderly patients. ${ }^{18}$ In Shimane Prefecture, over $20 \%$ of the population are elderly, and medication adherence and erroneous use of inhaled medications in elderly patients with asthma are important problems. We regularly hold seminars on inhalation guidance for pharmacists from regional pharmacies. We are training inhalation guidance experts. Improving adherence and techniques for taking inhaled medicines by strengthening hospital and pharmacy cooperation can lead to further improvements in asthma control in Shimane Prefecture.

We also examined asthma severity. In the RS group, the proportion of patients with moderate to severe asthma was high, but even in the GP group, $15.5 \%$ of all patients had severe asthma. The 2018 Asthma Prevention and Management Guideline recommends referring patients with uncontrolled asthma despite treatment step 3 or above to a specialist. The mainstay of asthma treatment is an inhaled medicine, but for patients with severe asthma, biological agents and bronchial thermoplasty should be considered. It is necessary to strengthen hospital and clinic cooperation so that patients with severe asthma and poor control treated by clinics can be introduced to specialized medical institutions.

This analysis has some limitations. The first limitation is that multiple confounding factors such as the chronic obstructive pulmonary disease (COPD), asthma-COPD Overlap (ACO), environment, comorbidities (such as gastroesophageal reflux disease, and allergic rhinitis) associated with the control of bronchial asthma have not been investigated in this study. In particular, the effects of COPD are difficult to rule out. The study included $18 \%$ of smokers over 10 pack-years. In the future, we would like to conduct a multivariate analysis, including factors that may have influenced this study, such as smoking history and the presence or absence of underlying diseases. The second limitation is that some facilities were asked to cooperate in the questionnaire in only one period. The number of 
patients from such institutions accounted for $28 \%$ of the total. The third limitation is the potential for bias in the selection of patients to be surveyed. We confirmed in advance the number of patients scheduled to see a medical institution in a month. The collection rate of the questionnaire was about $62 \%$ of the planned number of patients. Because we could not investigate the background of patients who did not cooperate with the questionnaire, we cannot rule out the possibility of bias in patient selection. In order to eliminate the second and third limitations, we would like to carry out additional studies with the same facilities and patient backgrounds in the future. The fourth limitation was the involvement of biological medications such as an anti-interleukin-5 antibody and the new disease concept of asthma and chronic obstructive pulmonary disease overlap. In 2006, the time of the first survey, these did not exist. Progress in treatment of bronchial asthma is rapid, and we did not evaluate these as factors that might be involved in higher asthma-related mortality in Shimane Prefecture. To elucidate factors associated with asthmarelated mortality other than the rate of ICS use, we will continue surveys in Shimane Prefecture. We believe that our work would lead to lower asthma-related mortality in the future.

\section{Conclusion}

We reported questionnaire survey results about asthma conducted in Shimane Prefecture over 6 years. The rate of ICS use and in the GP group had increased significantly and asthma control in GP group was improved significantly. On the other hand, problems related to asthma treatment in Shimane Prefecture, such as treatment of severe asthma and adherence to inhaled agents, were also clarified. We continue to need awarenessraising activities for asthma treatment among non-specialists. We also believe that it is our duty to strengthen collaboration among hospitals, clinics, and pharmacies.

\section{Acknowledgments}

We deeply appreciate the teachers and medical staff of 78 facilities that participated in this survey.

\section{Disclosure}

The authors report no conflicts of interest related to this work.

\section{References}

1. Ernst P, Spitzer WO, Suissa S, et al. Risk of fatal and near-fatal asthma in relation to inhaled corticosteroid use. JAMA. 1992;268 (24):3462-3464. doi:10.1001/jama.1992.03490240070039

2. Tada M, Kuraki T, Taooka Y, et al. Comparison of clinical management of young and elderly asthmatics by respiratory specialists and general practitioner. J Asthma. 2015;52(2):162-169. doi:10.3109/ 02770903.2014.928311

3. Nathan RA, Sorkness CA, Kosinski M, et al. Development of the Asthma Control Test: a survey for assessing asthma control. J Allergy Clin Immunol. 2004;113(1):59-65. doi:10.1016/j.jaci.2003.09.008

4. Morishima T, Otsubo T, Gotou E, et al. Physician adherence to asthma treatment guidelines in Japan: focus on inhaled corticosteroids. J Eval Clin Pract. 2013;19(2):223-229. doi:10.1111/j.13652753.2011.01708.x

5. Iwanaga T, Kumur M, Goren A, et al. Cross sectional patientreported survey on asthma control and associated burdens in Japanese patients with asthma in 2013. Ther Res. 2015;36:235-246.

6. Nelson HS, Chapman KR, Pyke SD, et al. Enhanced synergy between fluticasone propionate and salmeterol inhaled from a single inhaler versus separate inhalers. J Allergy Clin Immunol. 2003;112(1):29-36. doi:10.1067/mai.2003.1558

7. Seki R, Nagatomo Y, Yamaguchi T, et al. Ten-year questionnaire survey on adult asthma patients in Miyazaki Prefecture, Japan. Arerugi. 2014;63(6):794-804.

8. Tamaoki J, Kondo M, Sakai N, et al. Leukotriene antagonist prevents exacerbation of asthma during reduction of high-dose inhaled corticosteroid. The Tokyo Joshi Idai Asthma Research Group. Am J Respir Crit Care Med. 1997;155(4):1235-1240. doi:10.1164/ ajrccm.155.4.9105060

9. Tohda Y, Fujimura M, Taniguchi H, et al. Leukotriene receptor antagonist, montelukast, can reduce the need for inhaled steroid while maintaining the clinical stability of asthmatic patients. Clin Exp Allergy. 2002;32(8):1180-1186. doi:10.1046/j.13652745.2002.01440.x

10. Price D, Musgrave SD, Shepstone L, et al. Leukotriene antagonists as first-line or add-on asthma-controller therapy. $N$ Engl $J$ Med. 2011;364(18):1695-1707. doi:10.1056/NEJMoa1010846

11. Peters SP, Kunselman SJ, Icitovic N, et al. Tiotropium bromide stepup therapy for adults with uncontrolled asthma. $N$ Engl $J$ Med. 2010;363(18):1715-1726. doi:10.1056/NEJMoa1008770

12. Kerstjens HA, Engel M, Dahl R, et al. Tiotropium in asthma poorly controlled with standard combination therapy. $N$ Engl $J$ Med. 2012;367(13):1198-1207. doi:10.1056/NEJMoa1208606

13. Melani AS, Bonavia M, Cilenti V, et al. Inhaler mishandling remains common in real life and is associated with reduced disease control. Respir Med. 2011;105(6):930-938. doi:10.1016/j.rmed.2011.01.005

14. Tamura G, Ohta K. Adherence to treatment by patients with asthma and COPD:comparison between inhaled drugs and transdermal patch. Respir Med. 2007;101(9):1895-1902. doi:10.1016/j. rmed.2007.05.001

15. Williams LK, Pladevall M, Xi H, et al. Relationship between adherence to inhaled corticosteroids and poor outcomes among adults with asthma. $J$ Allergy Clin Immunol. 2004;114(6):1288-1293. doi:10.1016/j.jaci.2004.09.028

16. Hira D, Komase Y, Koshiyama S, et al. Problems of elderly patients on inhalation therapy:difference in problem recognition between patients and medical professionals. Allergol Int. 2016;65(4):444449. doi:10.1016/j.alit.2016.04.002

17. Hoskins G, McCowan C, Neville RG, et al. Risk factors and costs associated with an asthma attack. Thorax. 2000;55(1):19-24. doi:10.1136/thorax.55.1.19

18. GSK. Asthma Control Test. Available from: https://www.asthmacon troltest.com/en-au/welcome/. Accessed March 12, 2021. 


\section{Publish your work in this journal}

The International Journal of General Medicine is an international, peer-reviewed open-access journal that focuses on general and internal medicine, pathogenesis, epidemiology, diagnosis, monitoring and treatment protocols. The journal is characterized by the rapid reporting of reviews, original research and clinical studies across all disease areas. The manuscript management system is completely online and includes a very quick and fair peer-review system, which is all easy to use. Visit http://www.dovepress.com/ testimonials.php to read real quotes from published authors.

Submit your manuscript here: https://www.dovepress.com/international-journal-of-general-medicine-journal 